Canadian

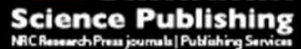

Canadian Journal of Forest Research Revue canadienne de recherche forestière

\title{
Geospatial information on geographical and human factors improved anthropogenic fire occurrence modeling in the Chinese boreal forest
}

\begin{tabular}{|r|l|}
\hline Journal: & Canadian Journal of Forest Research \\
\hline Manuscript ID & cjfr-2015-0373.R2 \\
\hline Danuscript Type: & Article \\
\hline Complete List of Authors: & $\begin{array}{l}\text { Guo, Futao; Fujian Agriculture and Forestry University, College of Forestry } \\
\text { Selvaraj, Selvalakshmi; Fujian Agriculture and Forestry University } \\
\text { Lin, Fangfang; Fujian Agriculture and Forestry University, Computer } \\
\text { Science } \\
\text { Wang, Guangyu ; University of British Columbia, Faculty of Forestry } \\
\text { Wang, Wenhui; Fujian Agriculture and Forestry University } \\
\text { Su, Zhangwen; Fujian Agriculture and Forestry University } \\
\text { Liu, Aiqin; Fujian Agriculture and Forestry University }\end{array}$ \\
\hline Keyword: & $\begin{array}{l}\text { Daxing'an Mountains, wildfire, geographically weighted logistic model, } \\
\text { driving factors, Human-caused fire }\end{array}$ \\
\hline \multicolumn{2}{|l}{} \\
\hline
\end{tabular}


1 Geospatial information on geographical and human factors improved anthropogenic fire

2 occurrence modeling in the Chinese boreal forest

3 Futao Guo ${ }^{a}$, Selvaraj Selvalakshmi ${ }^{a}$, Fangfang Lin ${ }^{b}$, Guangyu Wang, ${ }^{\text {acc }}$ Wenhui Wang ${ }^{a}$,

$4 \quad$ Zhangwen $\mathrm{Su}^{\mathrm{a}}$, Aiqin $\mathrm{Liu}^{\mathrm{a}^{*}}$

$5 \quad{ }^{\mathrm{a}}$ College of Forestry, Fujian Agriculture and Forestry University, Fuzhou, 350002, China

$6{ }^{\mathrm{b}}$ College of Computer and Information Science, Fujian Agriculture and Forestry University,

$7 \quad$ Fuzhou, 350002, China

$8 \quad{ }^{c}$ Faculty of Forestry, University of British Columbia, Canada, V6T 1 Z4

9 *Corresponding author. Tel: +86-591-83780261; Fax:+86-591-83780261; E-mail:

10 fjlaq@126.com (A. Liu) 
22 Geospatial information on geographical and human factors improved anthropogenic fire occurrence modeling in the Chinese boreal forest Abstract:

We applied a classic logistic regression (LR) together with a geographically weighted logistic regression (GWLR) to determine the relationship between anthropogenic fire occurrence and

27 potential driving factors in the Chinese boreal forest, and to test whether the explanatory power of the LR model could be increased by considering geospatial information of geographical and human factors using a GWLR model. Three tests, "all variables", "significant variables" and "cross-validation", were applied to compare model performance between the LR and GWLR models. Our results confirmed the importance of distance to railway, elevation, length of fire line and vegetation cover on fire occurrence in the Chinese boreal forest. In addition, GWLR model performs better than LR in terms of model prediction accuracy, model residual reduction and spatial parameter estimation by considering geospatial information of explanatory variables. This indicates that the global LR model is incapable of identifying underlying causal factors for wildfire modeling sufficiently. The GWLR model helped identify spatial variation between

37 driving factors and fire occurrence, which can contribute better understanding of forest fire occurrence over large geographic areas and the forest fire management practices may be 39 improved based on it.

Keywords: human-caused fire, wildfire, geographically weighted logistic model, driving factors, geospatial. 


\section{Introduction}

Forest fires are both a critical process in natural forests and a major cause of timber loss and human suffering (Fernandez-Pello 1994). Frequency of forest fires has increased significantly globally over the last decades. Forest fires have been the dominant disturbance regime in boreal forests since the last Ice Age, influencing energy flows and biogeochemical cycles, including local and global carbon cycling (Weber and Flannigan 1997). As in other boreal forests of the world, the Chinese boreal forest is threatened by fire (Stocks 1993; Shvidenko and Goldammer 2001). Anthropogenic fire is linked to human-mediated disturbance (encroachment, smoking, agricultural practices, hunting, fireworks, fire escape from locomotives and resident homes, recreation, industrial activities, tourism, intentional fires, etc.), which have played a critical role in fire occurrence in boreal forests. In Canada, two-thirds of all forest fires are caused by humans (Wotton et al. 2003). In the Siberian boreal forest, more than $85 \%$ of fires are linked to anthropogenic sources (Mollicone et al. 2006). In the Chinese boreal forest, human-caused forest fires account for approximately $60-80 \%$ of the total number of fires annually (Guo et al. 2015). Because of the significant influence of forest fire on the forest ecosystem and socio-economy, governments and researchers have devoted considerable effort to fire prediction.

1 Understanding the driving factors that influence human-caused fire occurrence is the key to fire prediction. Korovin (1996) indicated the influence of road distribution on anthropogenic fire. Niklasson and Granstrom (2000) and Wallenius et al. (2004) found that expansion of human settlements and increased population density drives fire occurrence in the boreal forest of northern Europe. Factors such as topography (i.e. elevation and slope) and forest type have also been found to be meaningful drivers (Mollicone et al. 2006; Syphard et al. 2007; RomeroCalcerrada et al. 2008; Martinez et al. 2009; Romero-Calcerrada et al. 2010). 
Logistic regression (LR) is the most commonly used model to predict the probability of fire occurrence and has been used successfully both at local (Vega-Garcia et al. 1995; Vasconcelos et al. 2001; Liu et al. 2012) and continental scales (Prasad et al. 2008; Martinez et al. 2009; Padilla and Vega-Garcia 2011). However, such a statistical model may be inappropriate for identifying the relationships between fire occurrence and influence factors because the assumptions of the non-spatial (stationarity) models, such as individual errors being independent of each other, may be violated. This leads to biased estimation of standard errors of model parameters and significance levels of statistical tests, and over-estimation of model $\mathrm{R}^{2}$ (Anselin and Griffith 1988). Researchers have indicated that spatial heterogeneity in the model parameters are more consistent with real-world situations and can be the result of random sampling variations and spatially varying relationships (Fotheringham et al. 1996; Foody 2003; Wang et al. 2005). Koutsias et al. (2005) found that the explanatory power of a global linear regression model increased considerably when it assumed varying relationships instead of constant ones.

Geographically weighted regression (GWR) is a useful exploratory analytical tool that can provide information on spatial non-stationarity in relationships between variables (Huang and Leung 2002; Matthews and Yang 2012). Zhang, Gove and Health (2005) found that GWR produced more accurate predictions for the response variable, and the residuals of the GWR model had more desirable spatial distributions including lower spatial autocorrelation compared to non-spatial models. In addition, GWR is an effective technique that enables regression model parameters to vary in space (Huang and Leung 2002; Foody2004; Wang et al. 2005). In the past decades, GWR has been applied successfully in many research areas, including forestry, ecology and social science (Zhang and Shi 2004; Wang, Ni, and Tenhunen 2005; Nakaya et al. 2005). In recent years, a GWR logistic model has also been used for forest fire prediction and its 
91 superiority has been identified by researchers (Koutsias et al. 2010; Martinezet al. 2013;

92 Rodrigues et al. 2014).

93 Taking the above perspectives into consideration, this study applies classical LR together with 94 a GWR logistic model to explore long-term forest fire occurrence patterns in the Chinese boreal 95 forest over the last decades. Specifically, the objectives are to: (1) identify potential driving 96 factors of fire occurrence, from topography, vegetation and human factors; (2) explore whether 97 the relationship between fire occurrence and influence factors are globally constant or spatially 98 variable; (3) further explore spatial variability by identifying significant factors that can 99 eventually explain spatially varying parameters; (4) compare the performance of GWLR and LR 100 models for fire occurrence. Our hypothesis is that geospatial information of factors will increase 101 the explanatory power of a forest fire prediction model.

\section{Materials and Methods}

\section{Study area}

China's boreal forests, located in the Daxing'an Mountains of northeastern China $\left(50^{\circ} 10\right.$ $10553^{\circ} 33^{\prime} \mathrm{N}$ and $121^{\circ} 12^{\prime}-127^{\circ} 00^{\prime} \mathrm{E}$ ), are the southernmost part of the global boreal forest biome 106 (Jiang et al. 2002). The total area of the forest covers $8.46 \times 10^{6}$ ha (Fig. 1). The dominant species

107 is Dahurian larch (Larix gmelinii Rupr.) and is normally accompanied by white birch (Betula 108 platyphylla Suk.), Mongolian pine (Pinus sylvestris L. var. mongolica Litv.), and Mongolian oak

109 (Quercus mongolica Fisch. ex Ledeb.). The Daxing'an Mountains are located in a cold-temperate 110 zone, with mean annual temperatures between $-2{ }^{\circ} \mathrm{C}$ and $4{ }^{\circ} \mathrm{C}$, and a range extending from $11152.3{ }^{\circ} \mathrm{C}$ to $39.0^{\circ} \mathrm{C}$. The mean total annual precipitation is between $350-500 \mathrm{~mm}$.

112 This region has the largest average annually burned area in China and is generally exposed to 113 extremely high fire risk. Between 1980 and 2005, there were more than 1,000 forest fires, 
114 including more than 600 human-caused fires, and a total area of burned forest amounting to 115 1,300,000 ha (Guo et al. 2015). In recent years, fires have become smaller (burned area), but 116 occur more frequently and more intensely than before (Chang et al.2007).

\section{Data collection}

118

120

121

122

123

124 125 126 127 128 129 130 131 132 133 134 135 136

\section{Dependent variable: fire record}

In this study, anthropogenic causes of forest fire included smoking, hunting, fireworks, and escaped fire from locomotives and resident homes. Anthropogenic fire data for the Daxing'an Mountains from 1980-2004 were provided by the Forest Fire Prevention office of the Heilongjiang Forestry bureau, China, including fire location, size, cause and date of occurrence. The fire data were acquired in a geo-database format and contained geographically referenced point locations of forest fires in the Daxing'an Mountains. Before 1990, the records of fire location were determined by the fire chief, who identified each fire location through a combined approach of fixed observation points in the forest and the Terrain and Forest Instruction Map (1:100 000)(Guo et al. 2015). Locations of fires after 1990 were recorded by GPS.

We randomly generated non-fire (i.e. control) points at a ratio of 1:1.5 as the fire ignition number (Catry et al. 2009; Chang et al. 2013) to meet the binary-variable requirement of LR and GWLR models. In addition, in order to improve the robustness of the method, random generation was applied one hundred times and then the non-fire points were extracted from all the randomly generated points as the 1:1.5 ratio. Consequently, the values for the dependent variables were assigned as ' 0 ' and ' 1 ' for control points $(n=905)$ and fire points $(n=620)$ respectively. We excluded non-fire (i.e. control) points located in water bodies or urban areas.

\section{Independent variables}

The independent variables consist of four categories, including topographic, vegetation, 
137 infrastructure and socio-economic factors. Details are provided in Table 1. The criteria for 138 independent variable selection were based on previous studies of fire occurrence.

139 Vegetation type

140 A digital vegetation map of China (1 km resolution) was downloaded from the Cold and Arid 141 Regions Science Data Center, China (http://westdc.westgis.ac.cn/). The data were gathered in 142 2000.We grouped polygons into the following five categories: needleleaf deciduous tree cover 143 (30.6\%), broadleaf deciduous tree (12.8\%), needleleaf evergreen tree (11.5\%), broadleaf 144 deciduous shrub (7.45\%), grass and agricultural crop (37.7\%). Forest vegetation types for each 145 fire and control point (i.e. non-fire) were extracted from the vegetation map layer using ArcGIS 146 10.0. We used the proportion of each vegetation type in which either a fire or control point was 147 located in the study area to develop the model. Vegetation cover

149 We used fractional vegetation cover (FVC) to represent the corresponding fuel amount of each 150 fire or control point. FVC is the vertical projection of the crown or shoot region of vegetation to 151 the ground surface within a unit area, expressed as a fraction or percentage (Purevdor 1998). The 152 FVC was calculated based on the normalized difference vegetation index (NDVI), which is a 153 simple graphical indicator that can be used to assess whether the target being observed contains 154 live green vegetation or not. Gutman and Ignatov (1997) proposed the relationship model 155 between NDVI and FVC as:

$$
F V C=\left(N D V I-N D V I_{\text {soil }}\right) /\left(N D V I_{\text {veg }}-N D V I_{\text {soil }}\right)
$$

157 where, $\mathrm{NDVI}_{\mathrm{veg}}$ and $\mathrm{NDVI}_{\text {soil }}$ are the NDVI of dense vegetation canopy and bare soil, 158 respectively. The NDVI dataset has a spatial resolution of $1 \mathrm{~km}$ and was provided by the 159 International Scientific and Technical Data Mirror Site, Computer Network Information Center, 
160

161

162

163

164

165

166

167

168

169

170

171

172

173

174

175

176

177

178

179

180

181

182

Chinese Academy of Sciences (http://www.gscloud.cn).

\section{Topography}

Elevation, slope and aspect were retrieved based on high-resolution $(25 \mathrm{~m})$ digital elevation model (DEM) data that was built in 2000 and collected from the National Administration of Surveying, Mapping and Geoinformation of China. Aspect was extracted as flat, north (315-45 $)$, east $\left(45-135^{\circ}\right)$, south $\left(135-225^{\circ}\right)$ and west $\left(225-315^{\circ}\right)$. The proportion of each aspect in the study area was calculated and used in developing the model, along with the other two topographic variables, elevation and slope.

\section{Infrastructure}

Human infrastructure has been identified as a main driver of wildfire occurrence by many studies (Martinez et al. 2009; Oliveira et al. 2012; Mundo et al. 2013; Oliveira et al. 2014). In this study, a number of tested variables (anthropogenic and environmental factors) were used based on previous studies, but other unique untested variables like number of inspection stations and length of fire line were also included. Other variables such as distance to the nearest railway, distance to the nearest road and others that can reflect the impact of distance between infrastructure and forest fire occurrence were also retrieved from a 1:250,000 Digital Line

Graphic (DLG) map which was built in 2000 and collected from the National Administration of Surveying, Mapping and Geoinformation of China. All data extraction was done in ArcGIS 10.0.

\section{Socio-economic factors}

Socio-economic factors included annual funding for forest fire prevention and per capita GDP. These variables have been used in other similar studies to represent the trend of potential changes in human activity, which may influence fire occurrence (Maingi and Henry 2007; Oliveira et al. 2014). The data was collected from the Heilongjiang Statistical Yearbook (2006) 
183 and the Local Chronicles of Forest Fire Prevention of Daxing'an Mountains (2005).

184

185

186

187

188

189

190

191

192

193

194

195

196

197

198

199

200

201

202

203

\section{Model description}

\section{Logistic Regression (LR)}

LR has been used for fire occurrence prediction and to examine the driving factors of fire occurrence in different regions of the world at various scales (Martell et al.1987; Vega-Garcia et al.1995; Martinez et al. 2009). It considersp $\mathrm{j}_{\mathrm{j}}$ as the probability of fire occurrence:

$$
\mathrm{p}_{\mathrm{j}}=\frac{\exp \left(\beta_{0}+\sum_{\mathrm{i}=1}^{\mathrm{n}} \beta_{\mathrm{i}} \mathrm{x}_{\mathrm{i}}\right)}{1+\exp \left(\beta_{0}+\sum_{\mathrm{i}=1}^{\mathrm{n}} \beta_{\mathrm{i}} \mathrm{x}_{\mathrm{i}}\right)}
$$

The corresponding probability $\mathrm{p}_{\mathrm{j}} \mathrm{can}$ be transformed to a linear function as below:

$$
\operatorname{logit}\left(\mathrm{p}_{\mathrm{j}}\right)=\log \left(\frac{\mathrm{p}_{\mathrm{j}}}{1-\mathrm{p}_{\mathrm{j}}}\right)=\beta_{0}+\sum_{\mathrm{i}=1}^{\mathrm{n}} \beta_{\mathrm{i}} \mathrm{x}_{\mathrm{i}}
$$

where, $X_{i}$ represents explanatory variables, $\beta_{0}$ is the intercept, and $\beta_{i}$ are coefficients of variables.

\section{Geographically Weighted Logistic Regression (GWLR)}

GWLR models can be considered an expansion of the standard LR model that incorporates geographical location into the models. The formula can be written as follows:

$\operatorname{logit}\left(\mathrm{p}_{\mathrm{j}}\right)=\log \left(\frac{\mathrm{p}_{\mathrm{j}}}{1-\mathrm{p}_{\mathrm{j}}}\right)=\beta_{0}\left(\mu_{\mathrm{j}}, \gamma_{\mathrm{j}}\right)+\sum_{\mathrm{i}=1}^{\mathrm{n}} \beta_{\mathrm{i}}\left(\mu_{\mathrm{j}}, \gamma_{\mathrm{j}}\right) \mathrm{x}_{\mathrm{i}}$

where, $\beta_{0}$ and $\beta_{\mathrm{i}}$ are GWLR model parameters specific to a location at $\left(\mu_{\mathrm{j}}, \gamma_{\mathrm{j}}\right)$ coordinates.

An important aspect of GWR modeling is determining a weighting function for estimating local model parameters. In GWR, the weighting function uses a distance function, resulting in observations closer in space, which are generally assumed to have a greater effect on local parameter estimates. In software GWR4, there are four kinds of kernel functions which can be used to determine the weighting matrix, including:(1) Fixed Gaussian,(2)Adaptive Gaussian, (3)

Fixed bi-square, and (4)Adaptive bi-square. Zhang et al. (2014) found that the Adaptive Gaussian 
204 has a better performance than other functions. The adaptive Gaussian can be expressed as 205 follows:

$206 \quad W_{i j}=\left\{\begin{array}{cc}\left(1-d_{i j}^{2} / \theta_{i(k)}\right)^{2} & d_{i j}<\theta_{i(k)} \\ 0 & d_{i j}>\theta_{i(k)}\end{array}\right.$

207 where, $W_{i j}$ is the weight value of an observation at location $\mathrm{j}$ for estimating the coefficient at 208 location $\mathrm{i} ; d_{i j}$ is the Euclidean distance between locations $\mathrm{i}$ and $\mathrm{j} ; \theta$ is the bandwidth size; $\theta_{i(k)}$ is the 209 kernel bandwidth size defined as the kth nearest neighbor distance. In this paper, we selected an 210 Adaptive Gaussian function to fit the model (Wang et al. 2005; Wu and Zhang 2013; Zhang et 211 al.2014).

\section{Model fitting and evaluation}

213

215

216

217

218

219

220

221

222

223

224

225

\section{Dataset division}

In this study, three types of tests (i.e. all variables test, significant variables test and crossvalidation test) were set up to compare the fitting effect of LR and GWLR models. To avoid the influence of sample distribution on the test results, the original dataset was randomly divided into training (60\%) and validation (40\%) samples (Rodrigues and de la Riva 2014). This procedure was repeated five times, applying a sampling with replacement method, resulting in five random sub-samples of data, each one with its own training and validation dataset.

\section{Model comparison procedure}

In the all variables test, all 13 variables are selected to test the model fit of the five subsamples and the complete samples. In the significant variables test, to select the significant variables, the forward Wald method was used in the LR model. To test the model fit of five subsamples, the principle of the quartile range of the estimated coefficients of GWLR is greater than \pm 1 standard deviation range of the estimated coefficients of LR (Zhang et al. 2014) was 
226

227

228

229

230

231

232

233

234

235

236

237

238

239

240

241

242

243

244

245

246

247

248

applied in the GWLR model. Variables that appeared to be significant in at least three of five intermediate models were included in the final model. To better compare the fitting results of the two models, a variable cross-validation test was conducted (i.e.significant variables from the GWLR model were used to fit the LR model, while significant variables from the LR were used to fit the GWLR model). We applied local polynomial interpolation in ArcGIS 10.0 to estimate the coefficients of each variable for the entire study area (Rodrigues et al. 2014).

\section{Model evaluation approaches}

SPSS19.0 was used for fitting the LR model and software GWR4.0 was used for fitting the GWLR model. The predictive performance of the two models was assessed by employing AIC, AICc and SSE. The smaller the value of AIC, AICc and SSE, the better the performance of the model fitting. Additionally, Receiver Operating Characteristic (ROC) curve analysis (Fielding Bell 1997) was used to evaluate prediction accuracy of the two models. The ROC curve was obtained by plotting sensitivity versus specificity for various probability thresholds. The area under the curve (AUC) is also often used to evaluate performance (Jimenez-Valverde 2012). An AUC of 0.5 indicates no discrimination; 0.5-0.69 poor discrimination; 0.7-0.79 reasonable discrimination; and 0.8-0.9 excellent discrimination (delHoyo et al. 2011). In other words, higher AUC indicates better performance of model fitting. Moreover, the Youden criterion can be derived from ROC curve analysis (Youden criterion=sensitivity + specificity-1). This can then be used to determine the cut-off point. If the predicted probability of fire occurrence is greater than the cut-off point, forest fires are considered to occur; otherwise, there is no occurrence of forest fires (Garcia et al. 1995; Catryet al. 2009). The prediction accuracy of five sub-samples and complete samples of two models were also calculated and results were compared.

We expressed the significant coefficient of each variable as a separate spatial layer by dividing 
249 the entire study area into $1 \times 1 \mathrm{~km}$ grids. In addition, we performed interpolation using Kriging

250 method on the estimated coefficients of each variable with complete dataset in ArcGIS 10.0

251 software. These different significant-coefficient layers were overlaid to identify the level of

252 spatial variability of variables in each grid. Finally, the Global Moran's I was used to calculate

253 spatial autocorrelation coefficients for the residuals of each model. The smaller the value of the

254 Global Moran's I, the smaller the residual spatial dependence, and the better the performance of 255 the model fitting, including more spatial relations (Zhang et al. 2014). The Global Moran's I was 256 calculated using the software package Rookcase added in Excel (Wu and Zhang 2013).

257 In order to eliminate the bias of model fitting, a multicollinearity analysis regarding 258 independent variables was performed before fitting the two models. We used the variance 259 inflation factor (VIF) to perform the multicollinearity diagnosis. A value of VIF $>5$ indicates a 260 significant collinearity between the independent variables, and the variables should be eliminated 261 (Wu and Zhang 2013).The total random points generated for fire points (620) and non-fire points 262 (905) were extrapolated for the entire study area.

263 Results and Analysis

264 Model fitting and prediction accuracy comparison

265 Comparison based on all variables

266 Absence of multicollinearity between our 13 variables meant that all variables could be used in 267 model fitting. All 13 variables were used to fit the LR and GWLR models. Estimated coefficients 268 in both models showed that elevation, number of inspection stations, and fire line were 269 negatively correlated; whereas variables like per capita GDP, distance to settlement, slope and 270 funding correlated positively with fire occurrence (Appendix Table A1). The relationship 271 between fire occurrence and the remaining variables was different between the two models. 
272 Coefficients of the other six variables (i.e. distance to railway, distance to river, distance to road,

273 forest type, aspect and vegetation cover) had both positive and negative effects in both the 274 models, but varied in space (Appendix Fig. A1).

275 Model fitting evaluation (Appendix Table A2) shows that, compared to the LR model, the 276 GWLR model has smaller AIC, AICc, SSE and higher prediction accuracy in each sample and 277 complete dataset, indicating a better model fit. The ROC curve (Appendix Fig. A2) also clearly 278 showed the superiority of GWLR model fit relative to LR.

\section{Comparison based on significant variables}

Table 2 shows the variables from the LR and GWLR models that were tested, their inclusion

281

282

283

284 285

in the model being based on prior determination of significance. The LR model selected three significant variables: elevation, per capita GDP and fire line. The GWLR model selected four significant variables: elevation, per capita GDP, distance to railway and vegetation coverage. The selected variables were used to fit the complete sample dataset in the LR and GWLR models (Table 2).

Estimated coefficients of the two models, using the complete sample dataset, shows that elevation and fire line were negatively correlated with forest fire occurrence. There was a positive relationship between fire occurrence and per capita GDP using the LR model. The spatial heterogeneity coefficients of two variables, such as distance to railway and vegetation coverage, showed both positive and negative relationships across the study area in the GWLR model (Fig. 3).

Model evaluation using significant variables (Table 3) showed that, compared to the LR model, the GWLR model had smaller AIC, AICc, SSE, and higher prediction accuracy in each samples and complete dataset. This indicates that the GWLR model had better goodness of fit. ROC 
295

296

297

298

299

300

301

302

303

304

305

306

307

308

309

310

311

312

313

314

315

316

317

curve analysis (Fig. 2) showed that the GWLR model had better predictive ability than the LR model. The prediction accuracy of the LR model ranged from $58.6 \%$ to $70.5 \%$, while the prediction accuracy of the GWLR model ranged from $65.2 \%$ to $79.9 \%$ (Table 3 ). As with the comparison based on all variables, the GWLR model showed higher prediction accuracy in each sample and the complete dataset compared to the LR model.

\section{Comparison based on cross-validation}

In order to better compare the fitting performance of the LR and GWLR models, a crossvalidation test was conducted. In the cross-validation test, each model was tested using the variables that were significant in the other model to identify the relative accuracy of each model (i.e. significant variables obtained from the GWLR were used to fit the LR model, and vice versa).The estimated coefficients of the two models using the samples and complete sample dataset are shown in Appendix Table A3.

The fitting results of the cross-validation test (Appendix Table A4) shows that, compared to the LR model, the GWLR model has smaller AIC, AICc, SSE, and higher prediction accuracy, indicating the advantage of its model fitting. ROC curve analysis (Appendix Fig. A3) shows that the GWLR model has better predictive accuracy than the LR model.

\section{Exploring the spatial variability of significant variables}

We focused this analysis on our GWLR model, since LR is incapable of showing the spatial variability of variable coefficients. In order to better show the spatial variation of coefficients of significant variables using GWLR for the entire study area, we performed spatial interpolation on estimated coefficients of each variable using the complete sample dataset in ArcGIS 10.0.

Fig. 3 shows that distance to railway, elevation and fire line have a significant negative influence in most parts of the study area. However, vegetation cover has a strong negative 
318 correlation with fire occurrence at the south corner of the study area, but a positive correlation in

319 the northeast of Daxing'an Mountains. It is worth noting that only four variables showed a 320 significant coefficient in space over the entire study area.

321 We identified the regions exhibiting different spatial variability based on GWLR model. All 322 coefficients were combined into one layer to identify regions of high and low spatial variability 323 (Fig. 4). Fig. 4 shows that the entire region had spatial variability, and the highest variation in 324 space occurred in the north and south portions of the study area.

325

329

\section{Spatial autocorrelation of residuals}

Global Moran's I of the GWLR model was smaller than for the LR model (Fig. 5). This indicates that, compared to the LR model, the GWLR model considers spatial autocorrelation more, which could be better for modeling and forecasting forest fire occurrence.

\section{Discussion}

We identified the strength of the GWLR model for predicting forest fire occurrence relative to the global LR using a series of tests (i.e. "all variables test", "significant variables test" and "cross-validation test"). We determined that geospatial information of explanatory factors should be considered when modeling anthropogenic fire occurrence in the Chinese boreal forest. Distance to railway, vegetation cover, elevation, and fire line were identified as the probable reasons underlying fire occurrence. Distance to railway was negatively correlated with anthropogenic fire occurrence in the Daxing'an Mountains, indicating that higher fire probabilities might be expected in areas close to railways. This is likely attributable to a variety of different sources, including errant sparks released from the steam engine, fire accidents that occur in the trains, and smokers travelling by train who throw lit cigarettes out the windows, as well as a lack of controlled burning and burning activities near the tracks. The map representing 
341 the distance to railway and locations of fire ignition is shown in the Appendix Fig. 4. It clearly

342 indicates that fire incidence happens closer to railway tracks. Railways reflect the transportation

343 corridor and according to the official record of fire causes, as well as other studies, some fires are

344 caused directly by human activities around railways (Stephens 2005; Romero-Calcerrada et al.

345 2008; Chang et al. 2013). The coefficient of distance to railway is significant in most of study

346 area (Fig. 3).

347 According to our study, anthropogenic fire is more likely to occur at low elevations. It is well

348 acknowledged that intensive human activities tend to be focused at low altitudes, which may

349 increase the likelihood of human-caused fire ignitions (Syphard et al. 2008; Oliveira et al. 2012;

350 Chang et al. 2013). In addition, the effects of altitude in weather conditions, vegetation cover and

351 soil moisture are less favorable to fire occurrence as altitude increases (González et al. 2006;

352 Vilar et al. 2010). The significant coefficient of the variable shows that the influence of elevation

353 is spread over most of the study area, with the strongest impact focused at the western region of

354 Daxing'an Mountains, which has high elevated terrains. It can be concluded that elevation may

355 result in greater influence on fire occurrence when compared to the other regions of the study 356 area.

357 Fire line represents local fire prevention activity. The local forest fire agencies burn the fire 358 line regularly, especially during the fire season, to remove understory vegetation cover and to 359 slow or stop the spread of forest fire, as well as identify the cause and origin of fire occurrence. 360 According to our findings, the length of the fire line is negatively correlated with fire occurrence. 361 This is because the length of burning the fire line increases every year if the intensity and area of 362 fire occurrence was higher in the previous year. This indicates that using fire lines works 363 efficiently for fire spread control. 
Vegetation cover represents the amount of available fuel during forest fires, which has been found to be an important indicator positively related to the forest fire ignition in previous study (Chuvieco et al. 2004). In this study, vegetation cover showed a significant, inverse relationship with fire occurrence in the southern region of the study area (Fig. 3). This seemed contrary to our previous understanding, and suggests that the spatial variation of forest fuel may not be the primary cause of local forest fire occurrence in the southern Daxing'an Mountains. Previous study by Lampin-Maillet et al. (2010) highlighted that, a low level of fire density occurs even if the vegetation cover is dense accompanied with more human settlements, which may explain our inconsistent findings.

Analysis on spatial variation indicates that, the variables specific to the regions play a major role in wildfire occurrence. Fig. 4 shows the areas influenced by a number of factors that vary on the spatial scale and have different spatial variability. Spatially varying relationships are associated with geographic characteristics of the dependent and independent variables. A very high spatial variability is found in the north and south parts of Daxing'an Mountains, with some regions impacted by two to three variables. However, Fig. 4 shows that only one variable influences fire occurrence in eastern Daxing'an Mountains. Due to the complexity of spatial influence of variables on fire, one global model seems to be insufficient to describe the relationship between fire occurrence and the underlying explanatory variables. The lower the number of predictors is easier to choose and apply fire prevention measures. However, it does not mean that higher number of significant variables cause more fire risk.

In addition, compared to the LR model, we found that the GWLR model reduced spatial autocorrelation errors, although it does not directly address spatial autocorrelation issues (Propastin and Kappas 2008). These findings are consistent with other researchers (Koutsias et al. 
387 388

2005). Wu and Zhang (2013) pointed out that a GWR model is not designed to model spatial autocorrelation. However, it estimates local rather than global parameters explicitly at each data point, which can account for spatial heterogeneity, especially for data with high spatial variability. In this study, the GWLR model shows better performance and accuracy than the LR model in relation to fire occurrence. However, GWLR may not suitable for making the general inference about the relationship between variables and fire occurrence. It is likely that the relationships are in fact global, but it is possible that the effects of these variables appear to vary locally due to interactions terms (e.g. the effect of vegetation cover on fire occurrence may switch from positive to negative depending on different human influence). As Jetz et al. (2005) concluded that GWR method may not be a complete alternative, but rather a good complement to global spatial regression modelling. Its power in illustrating local performance of predictor variables and their interaction with scale makes it a useful tool for forest fire analyses at the broad scale.

The study includes several caveats. There was no past or current information for variables such as distance to roads, distance to settlements, which likely change over time. The findings also limited by the data range, which only includes up to the year 2004. Future studies would benefit in testing model applicability by also including climatic variables that promote fire occurrence. The characteristics of the data collected from different data sources need to incorporate up to date information on variables for improving the paradigm of forest fire modeling. Addressing these caveats will help towards providing fundamental information upon which more sound forest fire management practices may be developed in a changing socioeconomic and environmental landscape.

\section{Conclusions}

In this study, classical LR modeling was used along with GWLR modeling to explain wildfire 
410 occurrence patterns in the Chinese boreal forest. Results indicate the importance of distance to 411 railway, vegetation cover, elevation and fire lines as underlying factors of fire occurrence, with 412 the latter two variables being negatively correlated with fire incidence. Compared to the LR 413 model, the GWLR model has a better performance in model prediction accuracy, model residual 414 reduction and spatial parameter estimation, indicating spatially varying relationships enhance the 415 explanatory power of global methods that do not appear sufficient to fully describe the 416 relationship between wildfire occurrence and the underlying explanatory factors. Indeed, the 417 GWLR model can complement the global LR model in helping to overcome the problem of non418 stationary variables, which means the geospatial information of explanatory variables should be 419 considered to improve anthropogenic fire occurrence modeling in the Chinese boreal forest.

420 Geographically weighted regression methods can be used to identify different variables, both 421 spatially and locally. This will help to isolate and interpret the specific factors responsible for fire 422 occurrence, which in turn provides information to design improved fire deployment activities for 423 local forest managers. In addition, the identification of regions with spatially varying 424 relationships can provide insight into fire management and policy and help to further our 425 understanding of the fire problem over large areas, while at the same time recognizing its local 426 character.

427 Acknowledgements

428 This research was funded by the National Natural Science Foundation of China (Grant No. 429 31400552); The Asia-Pacific Forests Net (APFnet/2010/FPF/001) Phase II.

430 References

431 Anselin, L., and Griffith, D.A. 1988. Do spatial effects really matter in regression analysis? 432 Papers in Regional Science. 65(1): 11-34. doi: 10.1111/j.1435-5597.1988.tb01155.x. 
433 Catry, F.X., Rego, F.C., Bacao, F.L., and Moreira, F. 2009. Modeling and mapping wildfire 434 ignition risk in Portugal. Int. J. Wildland Fire. 18(8): 921-931. doi.org/10.1071/WF07123.

435 Chang, Y., He, H.S., Bishop, I., Hu, Y., Bu, R., Xu, C., and Li X. 2007. Long-term forest 436 landscape responses to fire exclusion in the Great Xing'an Mountains, China. Int. J. 437

Chang, Y., Zhu, Z.L., Bu, R.C., Chen, H.W., Feng, Y.T., Li, Y.H., Hu, Y.M., and Wang, Z.C. 2013. Predicting fire occurrence patterns with logistic regression in Heilongjiang Province, China. Landscape Ecol. 28(10): 1989-2004. doi.10.1007/s10980-013-9935-4.

Chuvieco, E., Cocero, D., Riano, D., Martin, P., Martinez-Vega, J., de la Riva, J., and Perez, F. 2004. Combining NDVI and surface temperature for the estimation of live fuel moisture content in forest fire danger rating. Remote Sens. Environ. 92(3): 322-331. doi:10.1016/j.rse.2004.01.019.

delHoyo, V.L., Martin Isabel, M., and Martinez Vega, F. 2011. Logistic regression models for human-caused wildfire risk estimation: analysing the effect of the spatial accuracy in fire occurrence data. Eur. J. For. Res. 130(6): 983-996. doi.10.1007/s10342-011-0488-2.

Fernandez-Pello, A.C. 1994. The Challenge of fire prediction. Combust. Sci. Technol. (special silver anniversary issue). 98(4-6): 281-290. doi:10.1080/00102209408935413.

Fielding, A.H., and Bell, J.F. 1997. A review of methods for the assessment of prediction errors in conservation presence absence models. Environ. Conserv. 24(1): 38-49. Available from: http://journals.cambridge.org/ [accessed on 10 August 2015].

Foody, G.M. 2003. Geographical weighting as a further refinement to regression modeling: An example focused on the NDVI-rainfall relationship. Remote Sens. Environ. 88(3): 283-293. doi:10.1016/j.rse.2003.08.004. 
456 Foody, G.M. 2004. Spatial non-stationarity and scale-dependency in the relationship between 457 species richness and environmental determinants for the sub-Saharan endemic avifauna.

Fotheringham, A.S., Charlton, M., and Brunsdon, C. 1996. The geography of parameter space: an investigation of spatial non-stationarity. Int. J. Geogr. Inf. Syst. 10(5): 605-627. doi: $10.1080 / 02693799608902100$.

Garcia, C.V., Woodard, P.M., Titus, S.J., Adamowicz, W.L., and Lee, B.S. 1995. A logit model for predicting the daily occurrence of human caused forest fires. Int. J. Wildland Fire. 5(2): 101-111. http://www.publish.csiro.au/ [accessed on 24 May 2014].

González, J.R., Palahi, M., Trasobares, A., and Pukkala, T. 2006. A fire probability model for forest stands in Catalonia (north-east Spain). Ann. For. Sci. 64(5): 169-176. doi.org/10.1051/forest:2007047.

Guo, F.T., Innes, J.L., Wang, G.Y., Ma, X.Q., Sun, L., Hu, H.Q., and Su, Z.W. 2015. Historic distribution and driving factors of human-caused fires in the Chinese boreal forest between 1972 and 2005. J. Plant Ecol. 8(5): 480-490. doi: 10.1093/jpe/rtu041.

Gutman, G., and Ignatov, A. 1997. The derivation of the green vegetation fraction from NOAA/AVHRR Data for use in numerical weather prediction models. Int. J. Remote Sens. 19(8): 1533-1543. doi:10.1080/014311698215333.

Huang, Y., and Leung, Y. 2002. Analysing regional industrialisation in Jiangsu province using Geographically Weighted Regression. J. Geogr. Syst. 4(2): 233-249. doi:10.1007/s101090200081. 
477 Jetz, W., Rahbek, C., and Lichstein, J.W. 2005. Local and global approaches to spatial data 478 analysis in ecology. Global Ecol. Biogeogr. 14(1): 97-98. doi:10.1111/j.1466822X.2004.00129.x.

480

481

482

483

484

485

486

487

488

489

490

491

492

493

494

495

496

497

498

499

Jimenez-Valverde, A. 2012. Insights into the area under the receiver operating characteristic curve (AUC) as a discrimination measure in species distribution modeling. Global Ecol. Biogeogr. 21(4): 498-507. doi: 10.1111/j.1466-8238.2011.00683.x.

Johson, E.A., and Larsen, C.P.S. 1991. Climatically induced change in fire frequency in the southern Canadian Rockies. Ecology. 72(1): 194-201. doi: 10.2307/1938914.

Korovin, G.N. 1996. Analysis of distribution of forest fires in Russia. In Fire in ecosystems of Boreal Eurasia. Edited by J.G. Goldammer and V.V. Furyaev. Kluwer Academic Publishers. Boston. pp. 112-128.

Koutsias, N., Martinez-Fernandez, J., and Allgower Britta. 2010. Do factors causing wildfires vary in space? Evidence from Geographically Weighted Regression. GIsci. Remote Sens. 47(2): 221-240. doi: 10.2747/1548-1603.47.2.221.

Koutsias, N., Martinez, J., Chuvieco, E., Alligower, B. 2005. Modeling wildland fire occurrence in Southern Europe by a Geographically Weighted Regression approach. In Proceedings of the 5th International workshop on remote sensing and GIS applications to forest fire management: Fire Effects Assessment, Universidad de Zaragoza, Spain: 57-60. ISBN: 84$96214-52-4$

Lampin-Maillet, C., Jappiot, M., Long, M., Bouillon, C., Morge, D., and Ferrier, J. 2010. Mapping wildland-urban interfaces at large scales integrating housing density and vegetation aggregation for fire prevention in the South of France. J. Environ. Manage. 91(3): 732-741. doi:10.1016/j.jenvman.2009.10.001. 
500 Liu, Z., Yang, J., Chang, Y., Weisberg, P. J., and He, H.S. 2012. Spatial patterns and drivers of 501 fire occurrence and its future trend under climate change in a boreal forest of northeast China. Glob. Chang. Biol. 18(6): 2041-2056. doi: 10.1111/j.1365-2486.2012.02649.x.

503

504

505

506

507

508

509

510

511

512

513

514

515

516

517

518

519

520

Maingi, J.K., and Henry, M.C. 2007. Factors influencing wildfire occurrence and distribution in eastern Kentucky, USA. Int. J. Wildland Fire. 16(1): 23-33. doi.org/10.1071/WF06007.

Martell, D.L., Otukol, S., and Stocks, B.J. 1987. A logistic model for predicting daily peoplecaused forest fire occurrence in Ontario. Can. J. For. Res. 17(5): 394-401. doi:10.1139/x87068.

Martinez, J., Chuvieco, E., and Koutsias, N. 2013. Modelling long-term fire occurrence factors in Spain by accounting for local variations with Geographically Weighted Regression. Nat. Hazard. Earth Syst.Sci. 13: 311-327. doi: 10.5194/nhess-13-311-2013.

Martinez, J., Vega-Garcia, C., and Chuvieco, E. 2009. Human-caused wildfire risk rating for prevention planning in Spain. J. Environ. Manage. 90(2): 1241-1252. doi: 10.1016/j.jenvman.2008.07.005.

Matthews, S.A., and Yang, T. 2012. Mapping the results of local statistics: using geographically weighted regression. Demogr. Res. 26(6): 151-166. doi: 10.4054/DemRes.2012.26.6.

Mollicone, D., Eva, H.D., and Achard, F. 2006. Human role in Russian wild fires. Nature. 440(7083): 436-437. doi:10.1038/440436a.

Mundo, I.A., Thorsten, W., Rajapandian, K., and Thomas, K. 2013. Environmental drivers and spatial dependency in wildfire ignition patterns of northwestern Patagonia. J. Environ. Manage. 123: 77-87. doi:10.1016/j.jenvman.2013.03.011. 
521 Nakaya, T., Fotheringham, A.S., Brunsdon, C., and Charlton, M. 2005. Geographically Weighted 522 Poisson Regression for disease association mapping. Stat. Med. 24(17): 2695-2717. doi:

523

524 525

526

527

528

529

530

531

532

533

534

535

536

537

538

539

540

541

542

543 10.1002/sim.2129.

Niklasson, M., and Granstrom, A. 2000. Numbers and sizes of fires: long-term spatially explicit fire history in a Swedish boreal landscape. Ecology. 81(6): 1484-1499. doi: 10.2307/177301.

Oliveira, S., Oehler, F., San-Miguel-Ayanz, J., Camia, A., and Pereira, J.M.C. 2012. Modeling spatial patterns of fire occurrence in Mediterranean Europe using Multiple Regression and Random Forest. For. Ecol. Manage. 275: 117-129. doi:10.1016/j.foreco.2012.03.003.

Oliveira, S., Pereira, J.M.C., San-Miguel-Ayanz, J., and Lourenco, L. 2014. Exploring the spatial patterns of fire density in southern Europe using Geographically Weighted Regression. Appl. Geogr. 51: 143-157. doi:10.1016/j.apgeog.2014.04.002.

Padilla, M., and Vega-Garcia, C. 2011. On the comparative importance of fire danger rating indices and their integration with spatial and temporal variables for predicting daily humancaused fire occurrences in Spain. Int. J. Wildland Fire. 20(1): 46-58. doi.org/10.1071/WF09139.

Prasad, V.K., Badarinath, K.V.S., and Eaturu, A. 2008. Biophysical and anthropogenic controls of forest fires in the Deccan Plateau, India. J. Environ. Manage. 86(1): 1-13. doi:10.1016/j.jenvman.2006.11.017.

Propastin, P. 2012. Modifying geographically weighted regression for estimating above biomass in tropical rainforest by multispectral remote sensing data. Int. J. Appl. Earth Obs. 18(1): 8290. doi:10.1016/j.jag.2011.12.013.

Purevdorj, T.S., Tateishi, R., Ishiyama, T., and Honda, Y. 1998. Relationships between percent vegetation cover and vegetation indices. Int. J. Remote Sens. 19(18): 3519-3535. 
544

545

546

547

548

549

550

551

552

553

554

555

556

557

558

559

560

561

562

563

564

565

566

doi:10.1080/014311698213795.

Rodrigues, M., and de la Riva, J. 2014. An insight into machine-learning algorithms to model human-caused wildfire occurrence. Environ. Model. Softw. 57: 192-201. doi:10.1016/j.envsoft.2014.03.003.

Rodrigues, M., de la Riva, J., and Fotheringham, S. 2014. Modeling the spatial variation of the explanatory factors of human-caused wildfires in Spain using Geographically Weighted Logistic Regression. Appl. Geogr. 48: 52-63. doi: 10.1016/j.apgeog.2014.01.011.

Romero-Calcerrada, R., Barrio-Parra, F., Millington, J.D.A., and Novillo, C.J. 2010. Spatial modelling of socioeconomic data to understand patterns of human-caused wildfire ignition risk in the SW of Madrid (central Spain). Ecol. Model. 221(1): 34-45. doi:10.1016/j.ecolmodel.2009.08.008.

Romero-Calcerrada, R., Novillo, C.J., Millington, J.D.A., and Gomez-Jimenez, I. 2008. GIS analysis of spatial patterns of human-caused wildfire ignition risk in the SW of Madrid (central Spain). Landscape Ecol. 23: 341-354. doi: 10.1007/s10980-008-9190-2.

Shvidenko, A.Z., and Goldammer, J.G. 2001. Fire situation in Russia. IFFN. 24: 41-59. http://www.fire.uni-freiburg.de/iffn/country/rus/rus_26.htm.

Stephens, S.L. 2005. Forest fire causes and extent on United States forest service lands. Int. J. Wildland Fire. 14(3): 213-222. doi: 10.1071/WF04006.

Stocks, B. J. 1993. Global warming and forest-fires in Canada. For. Chron. 69(3): 290-293.doi: $10.5558 / \mathrm{tfc} 69290-3$

Syphard, A.D., Radeloff, V.C., Keely, J.E., Hawbaker, T.J., Clayton, M.K., Stewart, S.I., and Hammer, R.B. 2007. Human influence on California fire regimes. Ecol. Appl. 17(5): 13881402. doi:10.1890/06-1128.1. 
567 Syphard, A.D., Radeloff, V.C., Keuler, N.S., Taylor, R.S., Hawbaker, T.J., Stewart, S.I., and 568 Clayton, M.K. 2008. Predicting spatial patterns of fire on a southern California landscape.

569

570

571

572

573

574

575

576

577

578

579

580

581

582

583

584

585

586

587

588

589

Int. J. Wildland Fire. 17(5): 602-613. doi.org/10.1071/WF07087.

Vasconcelos, M.J.P., Silva, S., Tome, M., Alvim, M., and Pereira, J.M.C. 2001. Spatial prediction of fire ignition probabilities: comparing logistic regression and neural networks. Photogramm. Eng. Rem. S. 67(1): 73-81.

Vilar, L., Woolford, D.G., Martell, D.L., Pilar, and Martin, M. 2010. A model for predicting human-caused wildfire occurrence in the region of Madrid, Spain. Int. J. Wildland Fire. 19(3): 325-337. doi.org/10.1071/WF09030.

Wallenius, T.H., Kuuluvainen, T., and Vanha-Majamaa, I. 2004. Fire history in relation to site type and vegetation in Vienansalo wilderness in eastern Fennoscandia, Russia. Can. J. Forest Res. 34(7): 1400-1409. doi: 10.1139/x04-023.

Wang, Q., Ni, J., and Tenhunen, J. 2005. Application of a geographically-weighted regression analysis to estimate net primary production of Chinese forest ecosystems. Global Ecol. Biogeogr. 14(4): 379-393. doi: 10.1111/j.1466-822X.2005.00153.x.

Weber, M.G., and Flannigan, M.D. 1997. Canadian boreal forest ecosystem structure and function in a changing climate: Impacts on fire regimes. Environ. Rev. 5: 145-166. doi: 10.1139/a97-008.

Wotton, B.M., Martell, D.L., and Logan, K.A. 2003. Climate change and people-caused forest fire occurrence in Ontario. Climate Change. 60(3): 275-295. doi: 10.1023/A:1026075919710. Wu, W., and Zhang, L.J. 2013. Comparison of spatial and non-spatial logistic regression models for modeling the occurrence of cloud cover in northeastern Puerto Rico. Appl. Geogr. 37: 52-62. doi:10.1016/j.apgeog.2012.10.012. 
590 Wu, Z.E., He, H.S., Yang, J., Liu, Z.H., and Liang, Y. 2014. Relative effects of climatic and local 591 factors on fire occurrence in boreal forest landscapes of northeastern China. Sci. Total Environ. 493: 472-480. doi:10.1016/j.scitotenv.2014.06.011.

593

594

595

596

597

598

599

600

601

602

603

604

605

606

607

608

609

610

611

612

03

06

07

09

11

12

Xu, H.C., Li, Z.D., and Qiu, Y. 1997. Fire disturbance history in virgin forest in northern region of Daxinganling Mountains. Acta Ecologica sinica 17(4): 337-343. (in Chinese). http://en.cnki.com.cn/Article_en/CJFDTOTAL-STXB704.000.htm.

Zhang, H.J., Qi, P.C., and Guo, G.M. 2014. Improvement of fire danger modelling with geographically weighted logistic model. Int. J. Wildland Fire. 23(8): 1130-1146. doi.org/10.1071/WF13195.

Zhang, L., Gove, J.H., and Heath, L.S. 2005. Spatial residual analysis of six modeling techniques. Ecol. Model. 186(2): 154-177. doi:10.1016/j.ecolmodel.2005.01.007.

Zhang, L., and Shi, H. 2004. Local modeling of tree growth by geographically weighted regression. Forest Sci. 50(2): 225-244.

\section{4}




\section{Figure Captions}

614 Figure 1. Location map of study area with fire points

615

616 Figure 2. ROC Curves of the LR and GWLR models for five samples and complete dataset (CS)

617 with significant variables. The upper curve (GWLR) has greater area under the curve (AUC) than

618 that of LR, indicating GWLR has a relatively higher model fitting ability. AUC values of the 619 respective sample are given in parenthesis.

620

621 Figure 3. Significant areas of the estimated coefficient maps resulting from GWLR. If the $t$-value

622 of the estimated coefficient for a particular variable is $<-1.96$ or $>1.96$, then the variable has a

623 significant effect on fire presence; otherwise, the variable is considered as having no significant

624 effect on fire presence. Negative coefficients are mapped with cold colors (blue) and positive 625 coefficients with warm colors (orange to red). Full variable names, represented by abbreviations 626 here, are given in Table 1.

627

628 Figure 4. Regions where the coefficient of variables of the GWLR model were significant. The 629 degree of spatial variability is expressed by the number of variables exhibiting spatial variability. 630

631 Figure 5. Residual spatial autocorrelation coefficients plots of the LR and GWLR models, where 632 a: all variables test; b: significant variable test; c: cross-validation test. 


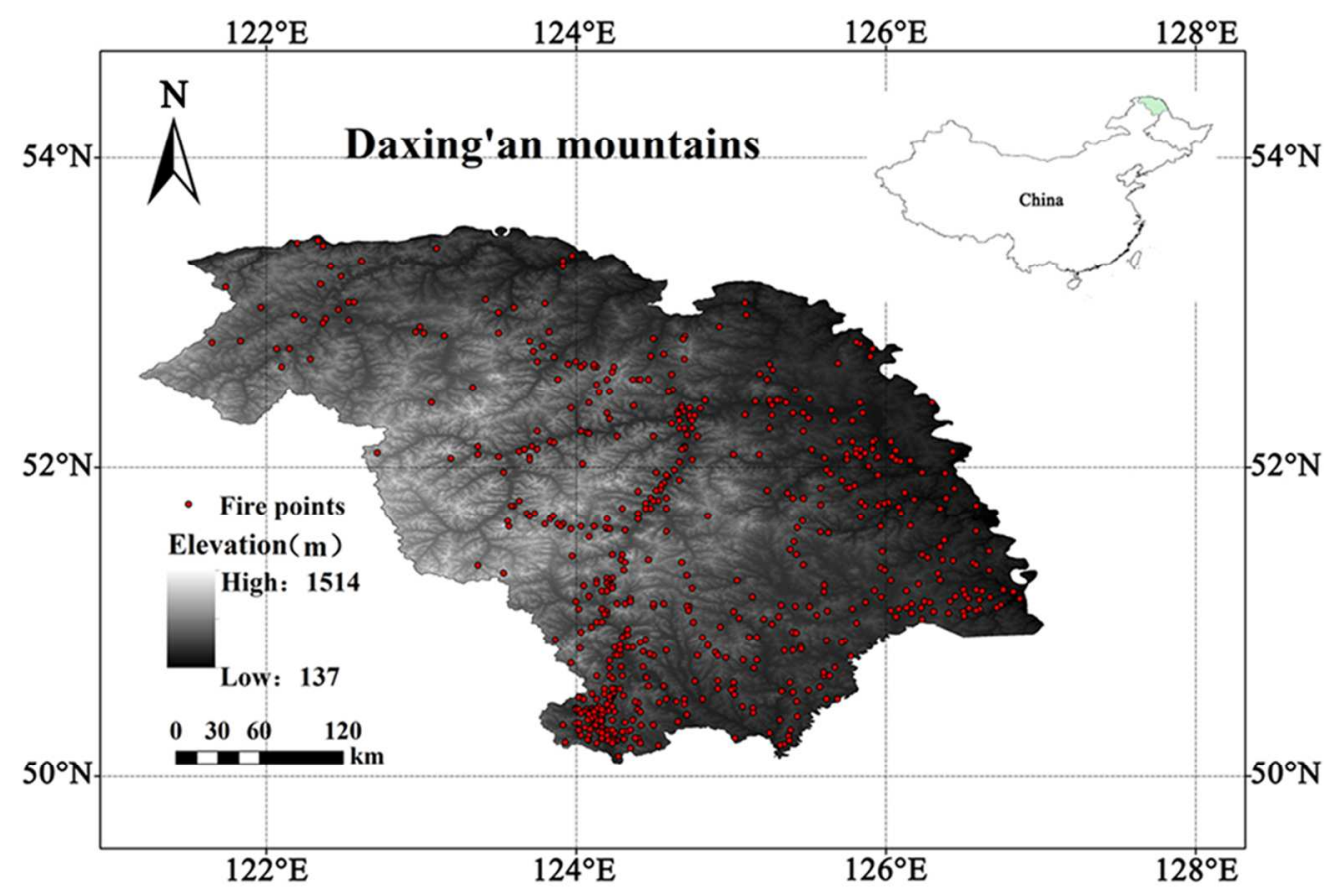

Figure 1

$99 \times 67 \mathrm{~mm}(300 \times 300$ DPI $)$ 

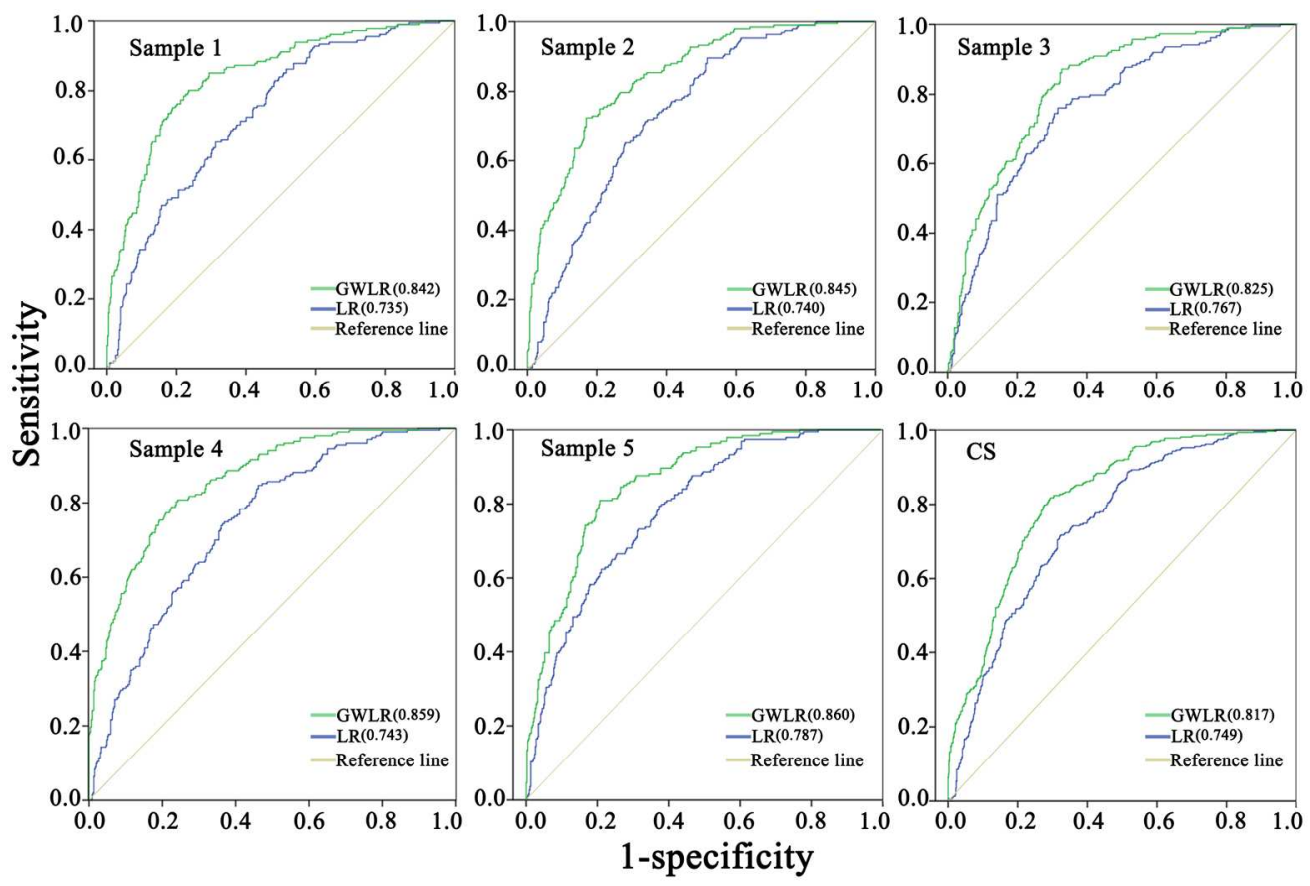

Figure 2

$180 \times 120 \mathrm{~mm}(300 \times 300$ DPI $)$ 

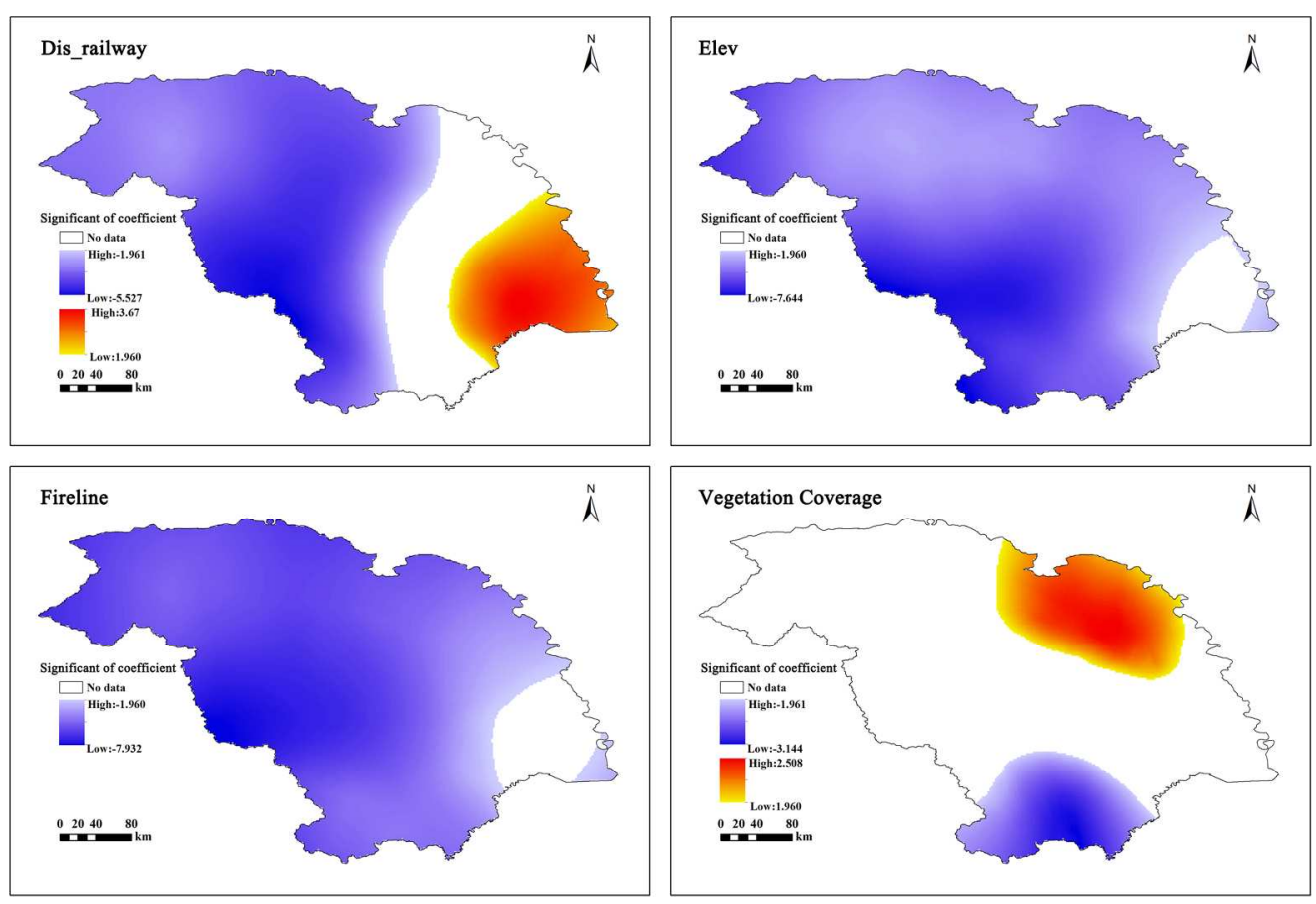

Figure 3

$180 \times 121 \mathrm{~mm}(300 \times 300 \mathrm{DPI})$ 


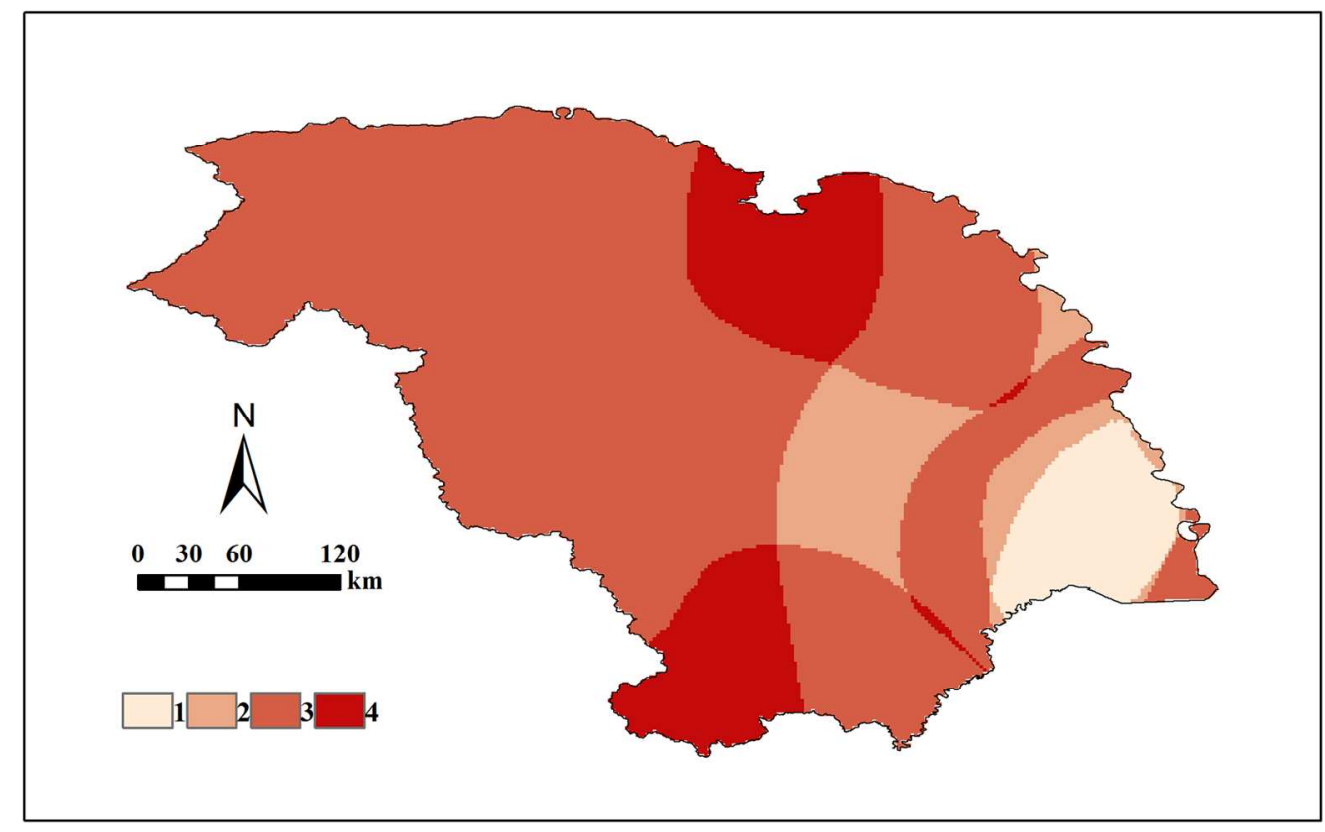

Figure 4

$160 \times 99 \mathrm{~mm}(300 \times 300 \mathrm{DPI})$ 


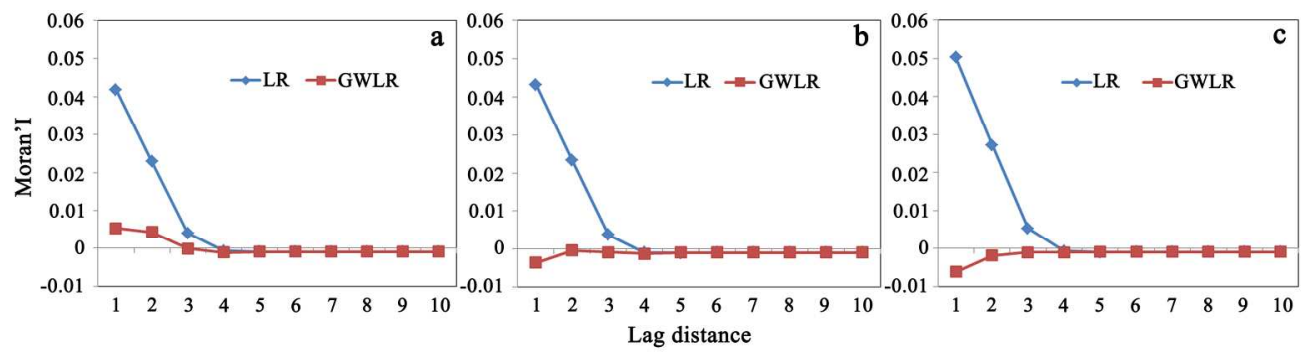

Figure 5

$199 \times 52 \mathrm{~mm}(300 \times 300 \mathrm{DPI})$ 
1 Table 1. Independent or predictor variables included in forest fire model development for

2 Daxing'an Mountains

\begin{tabular}{|c|c|c|c|}
\hline $\begin{array}{l}\text { Variable } \\
\text { Type }\end{array}$ & $\begin{array}{l}\text { Variable } \\
\text { Name }\end{array}$ & Code & Description \\
\hline \multirow{4}{*}{ Topographic } & Elevation & Elev & $\begin{array}{l}\text { The elevation of each fire point and control extracted from } \\
\text { a raster map of study area }\end{array}$ \\
\hline & Slope & Slope & $\begin{array}{l}\text { The slope of each fire point and control extracted from a } \\
\text { raster map of study area }\end{array}$ \\
\hline & Aspect & Aspect & $\begin{array}{l}\text { Proportion of each aspect class (flat, N, E, S, W) in the } \\
\text { study area }\end{array}$ \\
\hline & Forest type & Forest_type & Proportion of each forest type in the study area \\
\hline \multirow[t]{4}{*}{ Vegetation } & $\begin{array}{l}\text { Vegetation } \\
\text { cover }\end{array}$ & Veg_cover & $\begin{array}{l}\text { The fractional vegetation cover over the entire study area } \\
\text { at } 1 \mathrm{~km} \text { resolution }\end{array}$ \\
\hline & $\begin{array}{l}\text { Distance to } \\
\text { railway }\end{array}$ & Dis_railway & The distance between railway and fire point \\
\hline & $\begin{array}{l}\text { Distance to } \\
\text { river }\end{array}$ & Dis_river & The distance between river and fire point \\
\hline & $\begin{array}{l}\text { Distance to } \\
\text { road }\end{array}$ & Dis_road & The distance between road and fire point \\
\hline \multirow[t]{3}{*}{ Infrastructure } & $\begin{array}{l}\text { Distance to } \\
\text { settlement }\end{array}$ & Dis_sett & The distance between settlement and fire point \\
\hline & $\begin{array}{l}\text { Number of } \\
\text { inspection } \\
\text { stations }\end{array}$ & LNS & $\begin{array}{l}\text { The number of inspection stations that were used to } \\
\text { inspect the potential fire source with people who will } \\
\text { enter the mountains during the fire season }\end{array}$ \\
\hline & $\begin{array}{l}\text { Length of fire } \\
\text { line }\end{array}$ & Fireline & The length of fire line for fire prevention \\
\hline \multirow{2}{*}{$\begin{array}{l}\text { Socio-econom } \\
\text { ic }\end{array}$} & $\begin{array}{l}\text { Per capita } \\
\text { GDP }\end{array}$ & CGDP & Per capita GDP of the study area \\
\hline & Funding & Funding & Annual funding for forest fire prevention \\
\hline
\end{tabular}

3 
12 Table 2. Coefficient estimates of significant variables from LR and GWLR models

\begin{tabular}{|c|c|c|c|c|c|c|c|c|c|}
\hline Model & Statistics & $\beta_{\text {intercept }}$ & $\beta_{\text {dis-railway }}$ & $\beta_{2}-\beta_{7}$ & $\beta_{\text {elevation }}$ & $\beta_{\mathrm{CGDP}}$ & $\beta_{10-11}$ & $\beta_{\text {fire line }}$ & $\beta_{\text {vegetation cover }}$ \\
\hline \multirow[t]{6}{*}{ LR } & Estimate & 2.8736 & I & 1 & -0.0034 & 0.00014 & I & -0.0003 & / \\
\hline & Standard & & & & & & & & \\
\hline & & 0.3458 & / & / & 0.0005 & 0.00003 & l & 0.0001 & / \\
\hline & (s.d.) & & & & & & & & \\
\hline & Estimate -1 s.d. & 2.5278 & I & l & -0.0038 & 0.00011 & / & -0.0003 & / \\
\hline & Estimate +1 s.d. & 3.2195 & / & I & -0.0029 & 0.00016 & I & -0.0002 & / \\
\hline \multirow[t]{6}{*}{ GWLR } & Minimum & -0.8350 & -0.0336 & / & -0.0058 & l & I & -0.00068 & -2.0262 \\
\hline & $25 \%$ quartile & 0.5161 & -0.0210 & / & -0.0041 & / & l & -0.00052 & -0.8489 \\
\hline & Mean & 1.9052 & -0.0106 & / & -0.0032 & I & I & -0.00037 & 0.2487 \\
\hline & Median & 1.5866 & -0.0124 & / & -0.0030 & / & I & -0.00037 & 0.6086 \\
\hline & $75 \%$ quartile & 3.2335 & 0.0013 & I & -0.0025 & l & I & -0.00023 & 1.2608 \\
\hline & Maximum & 5.3785 & 0.0099 & / & -0.0010 & / & / & -0.00005 & 1.9520 \\
\hline
\end{tabular}

13 Note: $\beta_{2}$ : Distance to river; $\beta_{3}$ : Distance to road; $\beta_{4}$ : Distance to settlement; $\beta_{5}$ : Forest type; $\beta_{6}$ : Slope; $\beta_{7}$ : Aspect;

$14 \beta_{10}$ : Funding; $\beta_{11}$ : Number of inspection stations.

15

16

17

18

19

20

21

22 
Table 3. Comparison of the LR and GWLR models based on significant variables

\begin{tabular}{|c|c|c|c|c|c|c|c|}
\hline \multirow[b]{2}{*}{ Data } & \multirow[b]{2}{*}{ Model } & \multirow[b]{2}{*}{ AIC } & \multirow[b]{2}{*}{$\mathrm{AICc}$} & \multirow[b]{2}{*}{ SSE } & \multirow[b]{2}{*}{ Cut-off } & \multicolumn{2}{|c|}{ Prediction accuracy $(\%)$} \\
\hline & & & & & & $\begin{array}{c}\text { Training data } \\
(60 \%)\end{array}$ & $\begin{array}{c}\text { Validation data } \\
\qquad(40 \%)\end{array}$ \\
\hline \multirow{2}{*}{ Sample 1} & LR & 740.04 & 740.10 & 114.06 & 0.216 & 60.3 & 61.6 \\
\hline & GWLR & 610.27 & 612.11 & 75.54 & 0.329 & 77.4 & 65.2 \\
\hline \multirow{2}{*}{ Sample 2} & LR & 730.48 & 730.61 & 118.84 & 0.205 & 60.6 & 58.6 \\
\hline & GWLR & 619.71 & 621.66 & 92.88 & 0.394 & 79.9 & 69.3 \\
\hline \multirow{2}{*}{ Sample 3} & LR & 748.97 & 749.06 & 111.50 & 0.279 & 70.5 & 63.2 \\
\hline & GWLR & 640.65 & 641.45 & 100.44 & 0.296 & 72.9 & 67.3 \\
\hline \multirow[b]{2}{*}{ Sample 4} & LR & 725.03 & 725.26 & 119.86 & 0.242 & 63.4 & 66.8 \\
\hline & GWLR & 639.80 & 646.26 & 89.82 & 0.338 & 77.36 & 71.9 \\
\hline \multirow{2}{*}{ Sample 5} & LR & 712.71 & 712.80 & 108.84 & 0.254 & 67.6 & 62.0 \\
\hline & GWLR & 608.60 & 611.42 & 90.42 & 0.378 & 79.6 & 67.0 \\
\hline Complete & LR & 1194.80 & 1194.86 & 193.05 & 0.299 & \multicolumn{2}{|c|}{68.9} \\
\hline sample & GWLR & 1043.80 & 1044.34 & 167.66 & 0.337 & \multicolumn{2}{|c|}{73.9} \\
\hline
\end{tabular}

30

31 


\section{Appendix Tables \\ 2}

3 Table A1. Coefficient estimates of the all variables test from LR and GWLR models

\begin{tabular}{|c|c|c|c|c|c|c|c|c|c|c|c|c|c|c|c|}
\hline Model & Statistics & $\beta_{\text {Intercept }}$ & $\beta_{\text {Dis_railway }}$ & $\beta_{\text {Dis_river }}$ & $\beta_{\text {Dis_road }}$ & $\beta_{\text {Dis_sett }}$ & $\beta_{\text {Forest_type }}$ & $\beta_{\text {Slope }}$ & $\beta_{\text {Aspect }}$ & $\beta_{\text {Elev }}$ & $\beta_{\mathrm{CGDP}}$ & $\beta_{\text {Funding }}$ & $\beta_{\mathrm{LNS}}$ & $\beta_{\text {Fireline }}$ & $\overline{\beta_{\text {Veg_cover }}}$ \\
\hline \multirow[t]{4}{*}{ LR } & Estimate & 3.4763 & -0.0064 & -0.0121 & -0.0179 & 0.0071 & $\begin{array}{l}-0.1638 \\
\end{array}$ & 0.0400 & -2.2540 & -0.0038 & 0.00012 & 0.00030 & -0.0199 & -0.00023 & -0.3423 \\
\hline & Standard deviation (s.d.) & 0.6753 & 0.0041 & 0.0913 & 0.0151 & 0.0051 & 0.7578 & 0.0220 & 4.0006 & 0.0005 & 0.00003 & 0.00017 & 0.0034 & 0.00006 & 0.4258 \\
\hline & Estimate -1 s.d. & 2.8010 & -0.0105 & -0.1034 & -0.0329 & 0.0020 & -0.9216 & 0.0181 & -6.2545 & -0.0043 & 0.00009 & 0.00013 & -0.0233 & -0.00030 & -0.7681 \\
\hline & Estimate +1 s.d. & 4.1516 & -0.0023 & 0.0792 & -0.0028 & 0.0122 & 0.5941 & 0.0620 & 1.7466 & -0.0032 & 0.00015 & 0.00047 & -0.0165 & -0.00017 & 0.0834 \\
\hline \multirow[t]{6}{*}{ GWLR } & Minimum & 0.6195 & -0.0251 & -0.1081 & -0.0524 & 0.0033 & -0.0482 & 0.0174 & -10.3828 & -0.0053 & 0.00007 & 0.00002 & -0.0225 & -0.00044 & -1.4495 \\
\hline & $25 \%$ quartile & 2.2786 & -0.0185 & -0.0653 & -0.0386 & 0.0068 & 0.1901 & 0.0349 & -7.0371 & -0.0045 & 0.00010 & 0.00016 & -0.0204 & -0.00035 & -0.7495 \\
\hline & Mean & 3.3931 & -0.0117 & -0.0072 & -0.0250 & 0.0091 & 0.3779 & 0.0399 & -3.5474 & -0.0037 & 0.00012 & 0.00029 & -0.0184 & -0.00027 & -0.1432 \\
\hline & Median & 3.7563 & -0.0151 & -0.0303 & -0.0274 & 0.0090 & 0.3277 & 0.0400 & -2.9585 & -0.0038 & 0.00012 & 0.00026 & -0.0180 & -0.00026 & -0.0202 \\
\hline & $75 \%$ quartile & 4.5201 & -0.0042 & 0.0494 & -0.0177 & 0.0114 & 0.5285 & 0.0483 & -0.1119 & -0.0030 & 0.00014 & 0.00042 & -0.0169 & -0.00019 & 0.5212 \\
\hline & Maximum & 5.4462 & 0.0039 & 0.1289 & 0.0167 & 0.0160 & 1.2734 & 0.0560 & 2.1111 & -0.0020 & 0.00015 & 0.00055 & -0.0134 & -0.00014 & 0.8459 \\
\hline
\end{tabular}


Table A2. Comparison of LR and GWLR models with all variables

\begin{tabular}{|c|c|c|c|c|c|c|c|}
\hline \multirow[b]{2}{*}{ Data } & \multirow[b]{2}{*}{ Model } & \multirow[b]{2}{*}{ AIC } & \multirow[b]{2}{*}{$\mathrm{AICc}$} & \multirow[b]{2}{*}{ SSE } & \multirow[b]{2}{*}{ Cut-off } & \multicolumn{2}{|c|}{ Prediction accuracy $(\%)$} \\
\hline & & & & & & $\begin{array}{l}\text { Training data } \\
\qquad(60 \%)\end{array}$ & $\begin{array}{l}\text { Validation data } \\
\qquad(40 \%)\end{array}$ \\
\hline \multirow{2}{*}{ Sample 1} & LR & 705.67 & 706.32 & 113.83 & 0.279 & 67.4 & 68.2 \\
\hline & GWLR & 623.56 & 627.96 & 87.93 & 0.327 & 78.4 & 70.0 \\
\hline \multirow{2}{*}{ Sample 2} & LR & 720.70 & 721.36 & 116.98 & 0.288 & 69.1 & 69.3 \\
\hline & GWLR & 642.43 & 646.15 & 93.71 & 0.342 & 76.6 & 72.5 \\
\hline \multirow{2}{*}{ Sample 3} & LR & 686.29 & 686.95 & 109.27 & 0.281 & 71.1 & 66.7 \\
\hline & GWLR & 626.05 & 629.22 & 91.15 & 0.343 & 78.6 & 71.9 \\
\hline \multirow{2}{*}{ Sample 4} & LR & 728.93 & 729.58 & 118.11 & 0.270 & 65.9 & 72.2 \\
\hline & GWLR & 653.91 & 659.93 & 92.39 & 0.242 & 70.7 & 58.6 \\
\hline \multirow{2}{*}{ Sample 5} & LR & 666.25 & 666.91 & 106.04 & 0.300 & 72.0 & 65.8 \\
\hline & GWLR & 619.51 & 622.10 & 92.12 & 0.342 & 77.4 & 70.7 \\
\hline \multirow{2}{*}{$\begin{array}{c}\text { Complete } \\
\text { sample }\end{array}$} & LR & 1160.38 & 1160.77 & 189.84 & 0.281 & 67.8 & \\
\hline & GWLR & 1055.96 & 1057.80 & 162.90 & 0.348 & 75.4 & \\
\hline
\end{tabular}


Table A3. Coefficient estimates of variables from cross-validation of LR and GWLR models

\begin{tabular}{|c|c|c|c|c|c|c|c|c|c|}
\hline Model & Statistics & $\beta_{\text {Intercept }}$ & $\beta_{\text {Dis_railway }}$ & $\beta_{2-7}$ & $\beta_{\text {Elev }}$ & $\beta_{\mathrm{CGDP}}$ & $\beta_{10-11}$ & $\beta_{\text {Fireline }}$ & $\beta_{\text {Veg_cover }}$ \\
\hline \multirow[t]{6}{*}{ LR } & Estimate & 3.2210 & -0.00189 & / & -0.0035 & l & / & -0.0002 & -0.2584 \\
\hline & Standard deviation & & & & & & & & \\
\hline & & 1.0280 & 0.00194 & I & 0.0005 & / & I & 0.0001 & 0.1979 \\
\hline & (s.d.) & & & & & & & & \\
\hline & Estimate -1 s.d. & 2.1931 & -0.00383 & I & -0.0040 & ' & I & -0.0003 & -0.4563 \\
\hline & Estimate +1 s.d. & 4.2490 & 0.00005 & I & -0.0031 & / & l & -0.0002 & -0.0605 \\
\hline \multirow[t]{6}{*}{ GWLR } & Minimum & -0.7366 & / & / & -0.0069 & -0.00018 & l & -0.00067 & / \\
\hline & $25 \%$ quartile & 1.1867 & I & / & -0.0043 & 0.00001 & / & -0.00045 & l \\
\hline & Mean & 2.6304 & ' & ' & -0.0028 & 0.00008 & l & -0.00033 & ' \\
\hline & Median & 2.5722 & 1 & I & -0.0031 & 0.00008 & l & -0.00031 & l \\
\hline & $75 \%$ quartile & 3.9588 & 1 & I & -0.0012 & 0.00018 & l & -0.00024 & l \\
\hline & Maximum & 6.6053 & I & 1 & 0.0034 & 0.00024 & l & 0.00005 & I \\
\hline
\end{tabular}

Note: The corresponding coefficients for variables are $\beta_{2}$ : Distance to river; $\beta_{3}$ : Distance to road; $\beta_{4}$ : Distance to settlement; $\beta_{5}$ : Forest type; $\beta_{6}$ : Slope; $\beta_{7}$ : Aspect; $\beta_{10}$ : Funding; $\beta_{11}$ : Number of inspection stations. 
Table A4. Comparison of LR and GWLR models based on cross-validation

\begin{tabular}{|c|c|c|c|c|c|c|c|}
\hline \multirow[b]{2}{*}{ Data } & \multirow[b]{2}{*}{ Model } & \multirow[b]{2}{*}{ AIC } & \multirow[b]{2}{*}{$\mathrm{AICc}$} & \multirow[b]{2}{*}{ SSE } & \multirow[b]{2}{*}{ Cut-off } & \multicolumn{2}{|c|}{ Prediction accuracy $(\%)$} \\
\hline & & & & & & $\begin{array}{c}\text { Training data } \\
\qquad(60 \%)\end{array}$ & $\begin{array}{c}\text { Validation data } \\
\qquad(40 \%)\end{array}$ \\
\hline \multirow{2}{*}{ Sample 1} & LR & 695.31 & 695.40 & 120.73 & 0.245 & 62.5 & 59.5 \\
\hline & GWLR & 618.86 & 620.88 & 92.60 & 0.362 & 79.3 & 66.4 \\
\hline \multirow{2}{*}{ Sample 2} & LR & 708.73 & 708.82 & 124.24 & 0.250 & 62.0 & 62.9 \\
\hline & GWLR & 644.88 & 645.81 & 100.94 & 0.346 & 75.5 & 73.2 \\
\hline \multirow{2}{*}{ Sample 3} & LR & 681.06 & 681.15 & 118.62 & 0.262 & 64.1 & 60.3 \\
\hline & GWLR & 637.39 & 638.69 & 98.43 & 0.299 & 74.6 & 70.0 \\
\hline \multirow{2}{*}{ Sample 4} & LR & 722.49 & 722.58 & 126.29 & 0.270 & 62.6 & 65.4 \\
\hline & GWLR & 668.82 & 670.28 & 104.08 & 0.321 & 72.5 & 68.9 \\
\hline \multirow{2}{*}{ Sample 5} & LR & 660.26 & 660.36 & 120.33 & 0.271 & 63.8 & 61.0 \\
\hline & GWLR & 607.35 & 609.57 & 91.53 & 0.242 & 72.5 & 67.7 \\
\hline Complete & LR & 1153.77 & 1153.83 & 201.79 & 0.254 & \multicolumn{2}{|r|}{62.5} \\
\hline dataset & GWLR & 1040.49 & 1044.17 & 156.39 & 0.339 & \multicolumn{2}{|r|}{77.0} \\
\hline
\end{tabular}


Appendix Figures
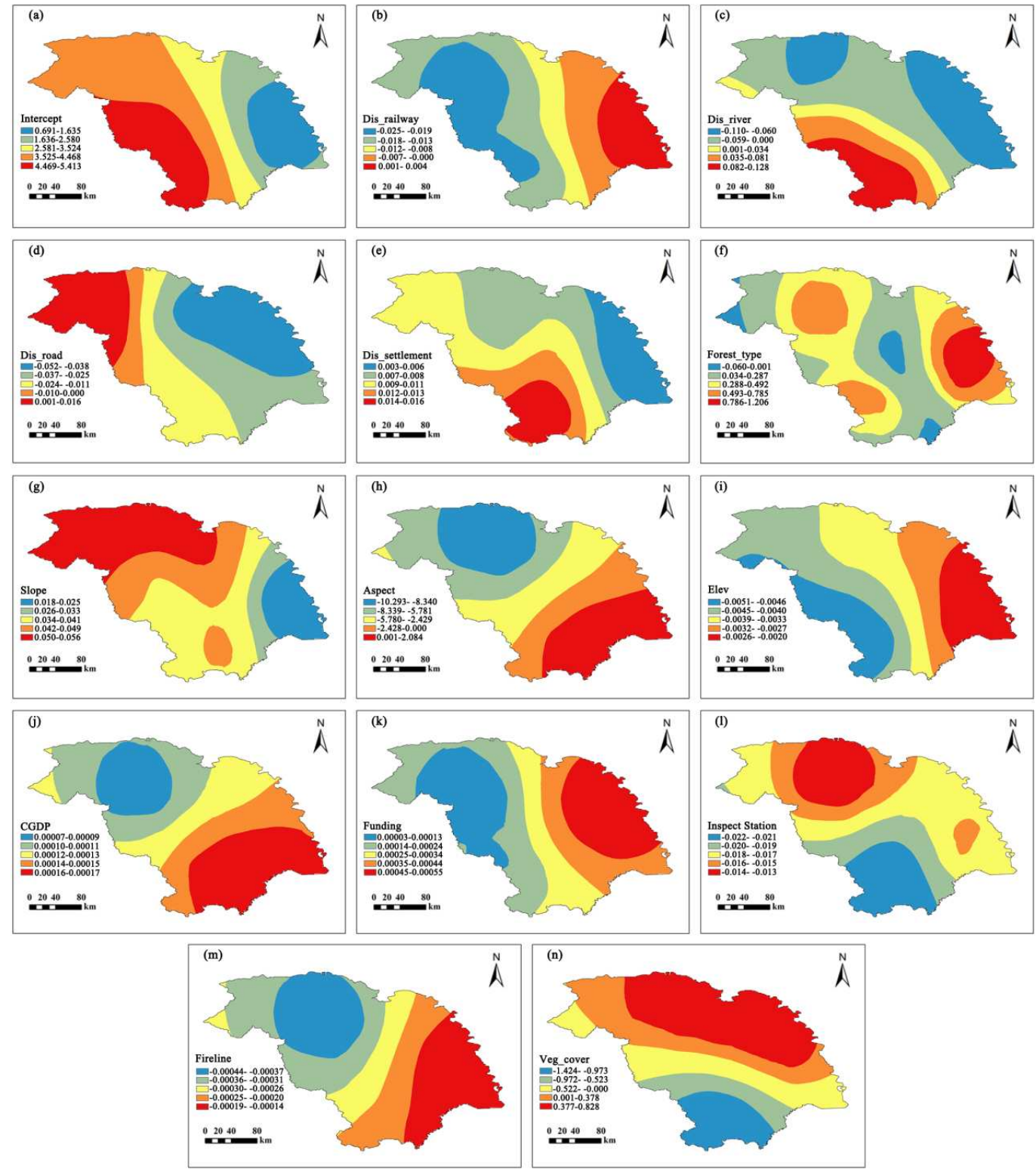

Fig. A1. Regression coefficients for all explanatory variables in the GWLR model. Negative coefficients are mapped with cold colors (blue) and positive coefficients with warm colors (red). 


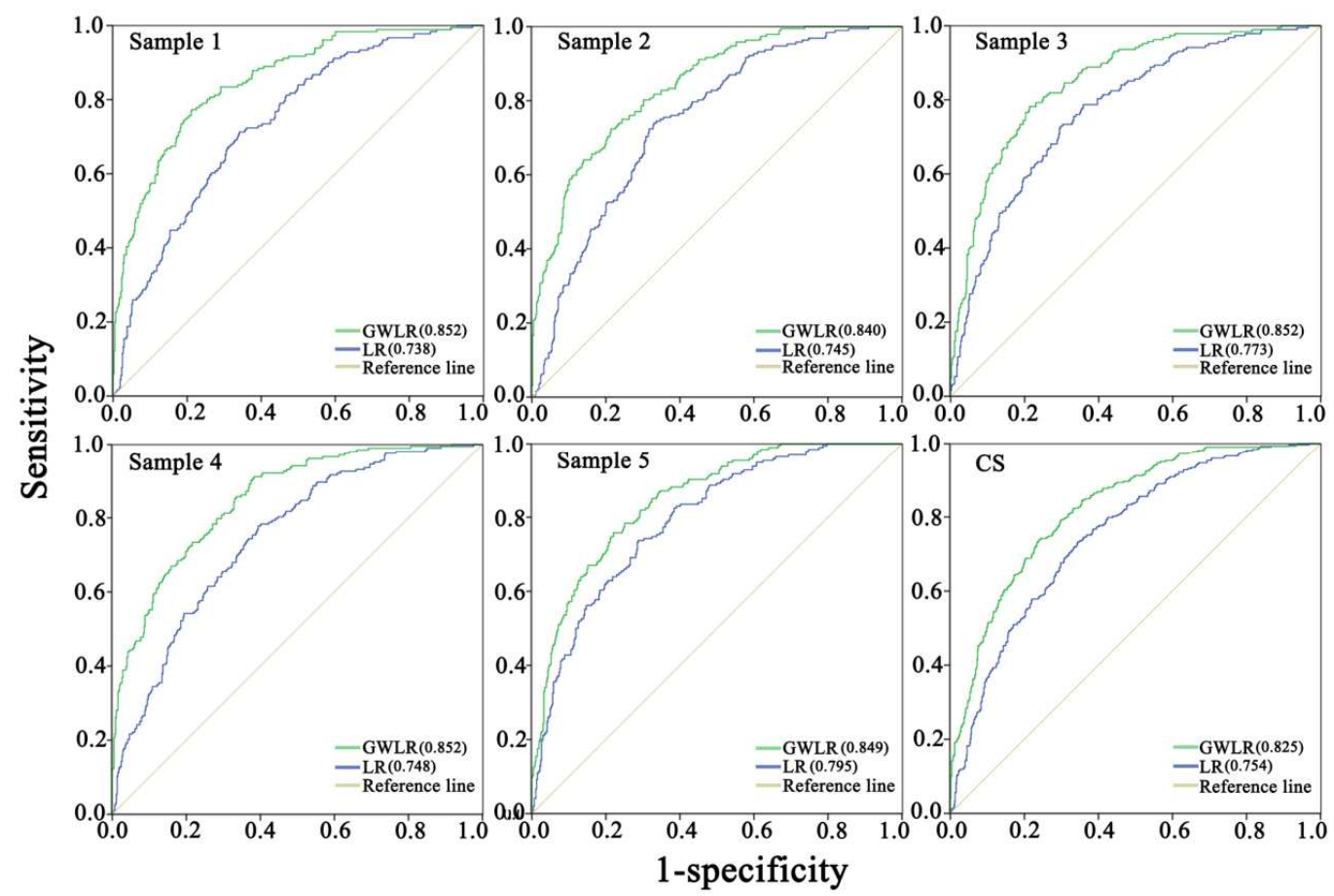

Fig. A2. ROC Curves of the LR and GWLR models for five samples and the complete dataset (CS) with all variables. The upper curve (GWLR) has greater area under the curve (AUC) than that of LR, indicating GWLR has a relatively higher model fitting ability. AUC values of the respective sample are given in parenthesis. 


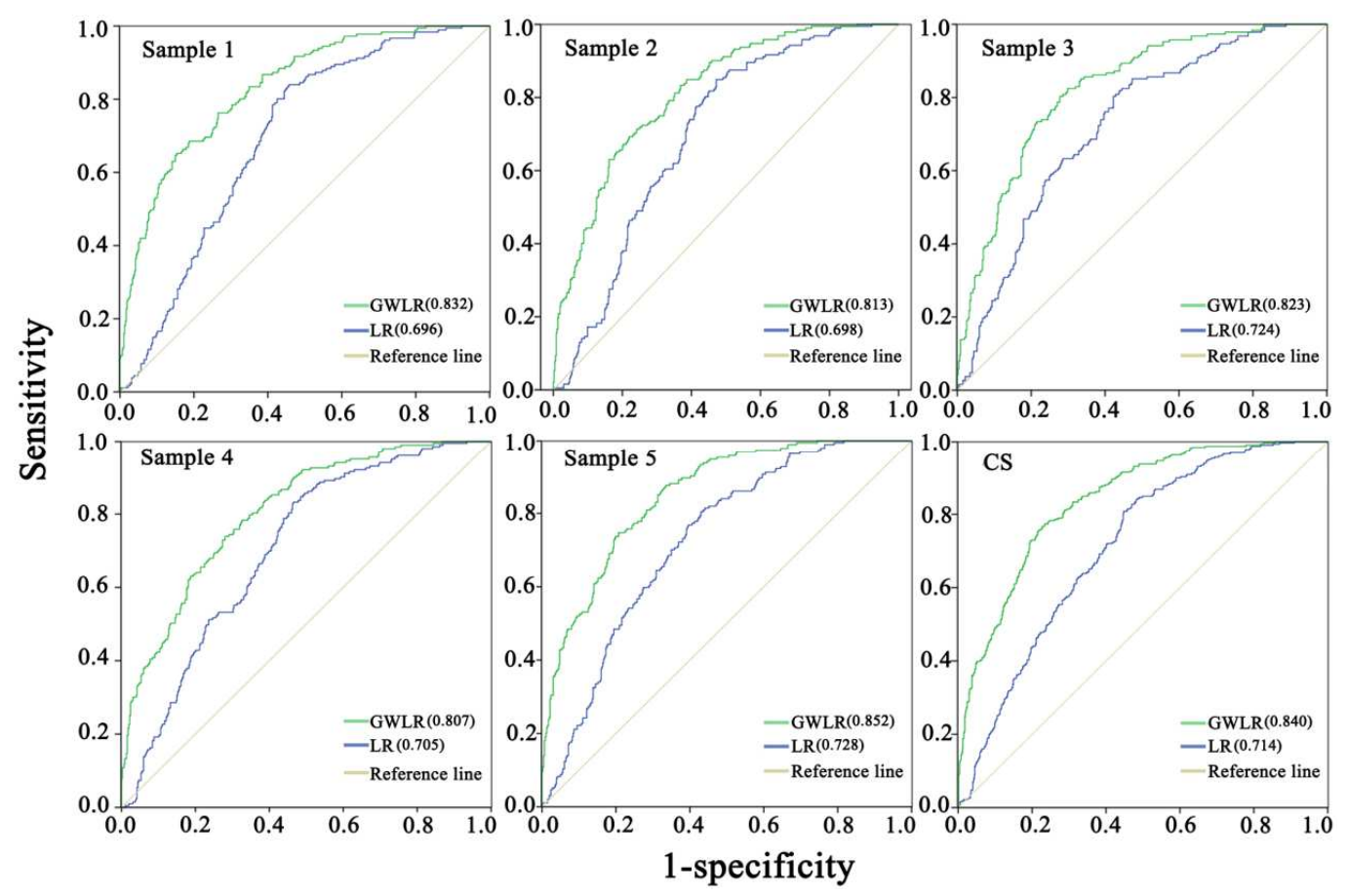

Fig. A3. ROC Curves of the LR and GWLR models for five samples and the complete dataset (CS) based on cross-validation. The upper curve (GWLR) has greater area under the curve (AUC) than that of LR, indicating GWLR has a relatively higher model fitting ability. AUC values of the respective sample are given in parenthesis. 


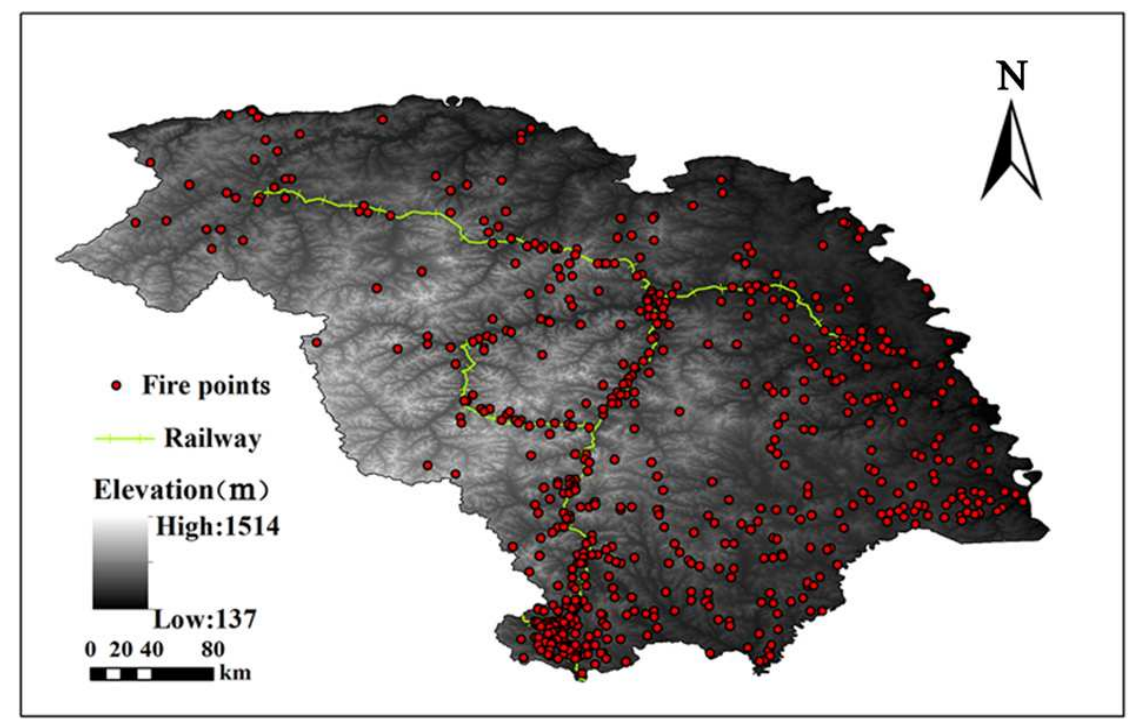

Fig. A4. The distribution of fire points and railway tracks in Daxing'an Mountains. 